\title{
MÚLTIPLAS ABORDAGENS NO DESENVOLVIMENTO DE CURRÍCULO
}

Na Revista número 107 inserimos uma nova seção - Educação, Ambiente e Saúde - que traz três artigos oriundos do 5 Congresso Internacional de Saúde, que aconteceu em julho de 2018 na Universidade do Minho, Braga, Portugal, em parceria com a Unijuí, ljuí, Brasil.

Os artigos do número 107 da Revista Contexto \& Educação articulam-se em torno das múltiplas abordagens no desenvolvimento do currículo, desde os fundamentos até as especificidades de cada área do conhecimento, como Ciências Naturais, Matemática, Geografia, Inglês, Ambientalização e Educação em Saúde.

$O$ artigo $O$ conhecimento do conhecimento: uma estratégia da escola para ensinar a viver de autoria de Celso Francisco Tondin, Sirlei Antoninha Kroth Gasparetto e Claudete Teresinha Junges, tematiza a relação entre complexidade, educação e saberes transdisciplinares, evidenciando que o desenvolvimento de um humanismo complexo nas escolas ocorre em experiências educativas e pode ser potencializado onde houver o desenvolvimento de um trabalho pedagógico que observe a aprendizagem e o desenvolvimento dos estudantes, a natureza complexa do conhecimento e potencialize a curiosidade epistemológica nos sujeitos envolvidos no processo de ensino-aprendizagem.

O artigo Educação e Barbárie: por uma economia política das desigualdades no espaço escolar, escrito por Ronaldo Queiroz Morais, compõe uma leitura crítica sobre os elementos de barbárie que habitam o social e a educação resultantes de políticas de construção de desigualdades. Assim, apresenta a barbárie moderna como produção de ambiente de placidez publicitária em meio à violência que predomina, sugerindo que a questão primeira da pedagogia crítica consiste em desbarbarizar o espaço escolar a partir de estratégicas e táticas de resistência e de transformação democrática.

Em Formação docente e reprodução de práticas: percepções de egressos de um curso de formação de professores para a educação profissional e tecnológica, Cristiane Berenice Caraveta dos Santos e Claudemir de Quadros apresentam resultados de uma pesquisa que consistiu em analisar as percepções de egressos do Programa Especial de Graduação para Formação de Professores para a Educação Profissional em relação à formação e atuação como professores, demonstrando que esses egressos, ainda que compreendam a necessidade de inovação e dinamismo nas aulas, continuam a se pautar pela reprodução de procedimentos tradicionais, entendendo não haver uma relação direta entre a frequência a um curso de formação de professores e um melhor desempenho profissional docente.

Amanda Carina Leal e Silva e Nelma Baldin, em Ambientalização curricular do Ensino Superior na universidade da região de Joinville - Univille: os cursos de Licenciatura e Direito, discutem as possibilidades do processo de ambientalização na Universidade da Região de Joinville - Univille -, acontecida nos cursos de Graduação (Licenciaturas e Direito) e efetuada entre 2015 e 2016. A partir da análise dos Projetos Pedagógicos dos Cursos (PPCs), as autoras sugerem uma discrepância entre a imagem que a uni- 
versidade consolidou enquanto "instituição verde" e o que conferem os currículos dos cursos, verificando que nos de Licenciaturas e Direito apresentam-se disciplinas com indícios de ambientalização, porém não o suficiente para considerar os cursos ambientalizados.

No artigo $O$ uso de recursos audiovisuais no ensino de ciências: uma análise em periódicos da área, Amanda Berk e Marcelo Rocha discutem a potencialidade dos recursos audiovisuais para os processos de ensino e aprendizagem no ambiente escolar, observando como ocorre a inserção desses recursos audiovisuais na prática docente.

Murilo Del Bianco Lima, Maria Júlia Corazza e Lourdes Aparecida Della Justina, no artigo Concepções acerca da história e epistemologia da biologia apresentadas em uma comunidade de prática, investigam as concepções acerca da epistemologia da biologia elucidadas por participantes de uma Comunidade de Prática, constituída por professores pesquisadores, pós-graduandos, graduandos e professores da Educação Básica. Com base nas observações desses participantes, caracterizam a biologia como uma ciência autônoma, mas que ainda não se encontra completamente unificada.

Édila Rosane Alves da Silva e Mara Elisângela Jappe Goi, no artigo Articulação entre resolução de problemas e a temática drogas como proposta metodológica para o ensino de química, apresentam os resultados de uma pesquisa desenvolvida com alunos do $3^{\circ}$ Ano do Ensino Médio de uma escola pública de ensino do município de Caçapava do Sul-RS -, cujo objetivo era identificar a resolução de problemas como metodologia no processo de ensino e aprendizagem por meio do uso de temáticas com alunos da Educação Básica. Os autores evidenciam dificuldades dos estudantes quanto aos aspectos relacionados às diferentes etapas de execução da proposta, revelando as potencialidades do uso da Resolução de Problemas sugeridas a partir de uma temática desenvolvida pelos alunos.

Em Um breve olhar sobre a Cienciometria: origem, evolução, tendências e sua contribuição para o ensino de ciências, Maurício Rodrigues Parra, Renato Xavier Coutinho e Edward Frederico Castro Pessano analisam contextualmente a Cienciometria, desvelam sua origem e desenvolvimento no Brasil e no mundo, apontam possíveis tendências, considerando sua importância para a avaliação da produção científica, e fornecem indicadores e subsídios para a comunidade acadêmica e sociedade em geral.

No artigo $O$ ensino de ciências e a aprendizagem significativa - reflexões sobre uma aula prática com a utilização de insetos, Luiz Antiogenes e Andrea Velloso da Silveira Praça aprofundam suas reflexões sobre o conceito de aprendizagem significativa e levantam possibilidades de mudança na prática pedagógica junto aos alunos da escola pública, entendendo que o significado da aprendizagem está no sujeito e não nas estratégias, abrindo possibilidades de repensar os argumentos que circulam no interior da escola.

Ellen Cristine Vivian Mendes Marques Bolzan e André Ary Leonel, no artigo Cultura surda e astronomia: investigando as potencialidades dessa articulação para o ensino de física, apresentam uma investigação sobre a potencialidade da Astronomia no processo de ensino-aprendizagem de Física para surdos, bem como as contribuições expostas pelas Tecnologias Digitais da Informação, compreendendo que o conhecimento da Libras e da Cultura Surda é indispensável para o planejamento de estratégias de 
ensino-aprendizagem e para a inclusão e a permanência dos sujeitos surdos na escola. Afirmam, então, que o tema Astronomia e o uso de TDIC favorecem o processo de ensino-aprendizagem, despertando o interesse dos envolvidos e possibilitando maior compreensão acerca dessa temática.

No artigo Análise dos conteúdos de física nos livros didáticos de ciências do nono ano do Ensino Fundamental aprovados pelo PNLD 2017, Savana dos Anjos Freitas e Agostinho Serrano de Andrade Neto apresentam o resultado da análise e categorização dos 13 livros didáticos de Ciências do nono ano do Ensino Fundamental aprovados pelo PNLD 2017. Nesse trabalho propõem uma compreensão do modo pelo qual os estudantes são apresentados à disciplina de Física no último ano do Ensino Fundamental e como os conteúdos são distribuídos no livro.

No texto Contribuições ao estudo da atividade de ensino: a questão dos motivos dos professores de matemática, luri Kieslarck Spacek e Vidalcir Ortigara analisam, na perspectiva teórica de Leontiev, os motivos e necessidades dos professores de Matemática em sua prática docente, demonstrando que essas necessidades estão centradas na subjetividade e que os aspectos da vida cotidiana estão se estabelecendo como características estruturadoras das atividades de ensino.

As autoras Marli Teresinha Quartieri, Bruna dos Santos, leda Maria Giongo e Márcia Jussara Hepp Rehfeldt, no artigo Programa observatório da educação: possibilidades para (re)pensar o currículo de matemática do Ensino Fundamental, socializam as percepções de um grupo de professores da Educação Básica sobre o conjunto de ações desenvolvido em uma pesquisa/intervenção vinculada ao Programa Observatório da Educação (Edital Inep/Capes 049/2012).

No artigo A prática competente do professor universitário: por uma emancipação discente, Jairo de Carvalho Guimarães discute questões que envolvem as estratégias didático-pedagógicas subjacentes à prática cotidiana do professor universitário do curso de Administração, apontando para a percepção de que mudanças requeridas pelo estrato da sociedade em termos de formação profissional em nível superior perpassam pelo pleno comprometimento do professor.

Emanuel Lindemberg Silva Albuquerque e Luciano Mascarenhas da Silva Sousa, no artigo Arquitetura escolar, condições térmicas e ensino-aprendizagem: análises e reflexões, analisam a estrutura física de uma Unidade Escolar, localizada no município de Teresina/PI, em suas adequações quanto às condições relacionadas ao conforto térmico, associado ao processo de ensino/aprendizagem dos alunos em geografia.

Nilton Hitotuzi, no artigo Challenges for non-american-english-speaking teachers in english language classrooms in Brazil, discute os desafios para o ensino de inglês pelos professores quando se trata da variante Britânica ou Americana.

\section{SEÇÃO EDUCAÇÃO, AMBIENTE E SAÚDE}

No artigo Instrumentos para indicação, avaliação e instituição de tecnologia assistiva: revisão sistemática, Lígia Maria Presumido Braccialli, Ana Carla Braccialli e Rita de Cássia Tibério Araújo discutem sobre os instrumentos disponíveis para a indicação, avaliação e instituição de tecnologia assistiva, afirmando que, apesar de haver diferentes instrumentos, poucos estão disponíveis na língua portuguesa. 
Maria Inês Bomfim e Valeria Morgana Goulart, no artigo Formação docente para o trabalho em saúde: o "notório saber" e outras propostas de precarização e flexibilização, problematizam as tentativas de flexibilização dos requisitos ao trabalho docente, bem como o esvaziamento da política de formação de professores que, enaltecendo o saber profissional construído na prática, secundarizam aspectos da formação que não estão presentes na vida cotidiana dos profissionais da área de saúde. As autoras defendem que a vida cotidiana, embora importante, não é a única esfera da vida social, concluindo que as esferas não cotidianas mais complexas podem ser decisivas no processo formativo de professores para produzir o questionamento sobre o pensar, o sentir e o agir em saúde, evitando-se que a vida cotidiana se hipertrofie em relação às outras esferas, perdendo-se o poder da reflexão e da crítica sobre a realidade em que se atua.

Michelle Alves Vasconcelos Ponte, Sandra Celina Fernandes Fonseca e Maria Isabel Martins Mourão Carvalhal, no artigo A universidade como espaço promotor de culturas saudáveis, propõem estratégias que estimulem a adoção de comportamentos ativos e saudáveis a serem desenvolvidas nas Instituições de Ensino Superior (IES). É um estudo transversal, exploratório, realizado em uma IES no Ceará-Brasil, com 324 universitários, ingressantes e concluintes, nas áreas da Saúde, Humanas e Exatas, em que foi utilizado o questionário ISAQ-A.

Boa leitura!

Maria Cristina Pansera-de-Araújo 